\title{
CONTRIBUIÇÃO DA EDUCAÇÃO AMBIENTAL NO ÂMBITO DE DESENVOLVIMENTO DE GESTÃO RISIDUAL NO INSTITUTO AGRÁRIO CHÓKWĖ, MOÇAMBIQUE
}

Munossiua Efremo Macorreia ${ }^{1}$

Resumo: Atualmente a Educação Ambiental, é o único instrumento que desempenha maior influência na sensibilização nas pessoas no âmbito social, econômico e socioambiental, proporcionando consciência que possibilita contribuir positivamente na construção duma sociedade sustentável que envolve a participação ativa dos munícipes, visando a diminuição da quantidade de matéria orgânica e produtos reutilizáveis ou recicláveis disponível nos resíduos sólidos de origem domiciliar, comercial e industrial. Para o efeito, a pesquisa em causa é qualitativa, com abordagem descritiva, exploratória e empírica e permitiu ao pesquisador fazer a observação, seleção, consolidação, análise documental e a entrevista semiestruturada através de contato direto com os formandos, agentes públicos, professores e a comunidade em geral. Assim, foram realizadas entrevistas com 90 formandos do primeiro, segundo e terceiro ano do curso de Agropecuária, com uma amostra de 27 formandos, subdivididas em dois grupos: Sendo 15 homens com $55.6 \%$ e 12 mulheres com $44.4 \%$. Todos foram interrogados sobre conteúdos relacionados com a gestão dos resíduos sólidos, visando identificar a quantidade e tipo de resíduo gerado pela escola, na perspectiva de responder a seguinte questão: Quais os níveis de conhecimentos e as práticas educativas que podem ajudar no âmbito escolar para a mitigação e a gestão seletiva dos resíduos sólidos? Assim, O presente estudo tem como objetivo: Analisar a contribuição da Educação Ambiental na coleta seletiva do lixo, de forma que os aprendizes possam assumir posições significativas com valores referentes ao seu comportamento no âmbito da gestão dos resíduos sólidos, identificando qual o nível de compreensão em relação ao meio ambiente em seu dia-a-dia. Face a isso, os resultados revelam a existência de carência nos serviços de limpeza pública oferecidos pelo município, o que desestimula os aprendizes a separação dos resíduos, já que não há coleta seletiva.

Palavras-chave: Educação Ambiental; Gestão dos Resíduos Sólidos; Instituto Agrário Chókwè. ${ }^{1}$ Instituto Agrario de Chokwe - $\quad$ FUNIBRE-Universidade Internacional - E-mail:
efremomunossiua@yahoo.com.br 
Abstract: Nowadays the environmental education is the only instrument that plays a greater role in sensitizing people in the social, economic and socio-environmental spheres, providing a conscience that makes it possible to contribute positively to the construction of a sustainable society that involves the active participation of the citizens, aiming to reducing the amount of organic matter and reusable or recyclable products available in domiciliary, commercial and industrial solid waste. For that purpose, was developed a qualitative research, with a descriptive approach. The researcher made observation, selection, consolidation, documental analysis and semi-structured interviews through direct contact with the students, public agents, teachers and the community in general. Thus, the interviews were conducted with 90 students of first, second and third levels of Agriculture Course. Were used a sample of 27 students, subdivided into two groups: 15 men (55.6\%) and 12 women (44.4\%). All students were questioned about contents related to solid waste management, in order to identify the quantity and type of waste generated by the school, in order to answer the following question: What levels of knowledge and educational practices can help the mitigation and selective management of solid waste in the school? Thus, the present study aims to: Analyze the contribution of environmental education in the waste selective collection in order to move the students to assume significant positions with values referring to their behavior in the scope of solid waste management, identifying the level of understanding about the environment in their daily life. The results reveal the lack of public cleaning services offered by the municipality, which discourages students to separate the waste, because there's no selective collection.

Keywords: Environmental Education, Solid Waste Management.

\section{Introdução}

Nos transformamo-nos numa sociedade de "deita fora", e produzimos mais resíduos sólidos do que a própria comida para assegurar a segurança alimentar para comunidade em geral e não sabemos o que fazer com os resíduos espalhados por ai à fora, provocando doenças, atraindo baratas, ratos, moscas, cobras, ratazanas e outras pragas portadoras de doenças prejudiciais à saúde pública.

Essa situação, torna-se mais complicada no território Moçambicano pelo fato do crescimento populacional urbana que não foi acompanhado, segundo o plano diretor da gestão de resíduos sólidos urbanos da cidade de Maputo (2008), esclarece que:

Depois da luta de libertação nacional e a conquista da independência em 1975, as cidades de Moçambique passaram a estar administrativamente dependentes do Governo Central, no que tange aos recursos financeiros. Muitas estruturas administrativas utilizando no período colonial mantiveram-se até os dias de hoje. O crescimento das cidades Moçambicanas não foi acompanhado devidamente a evolução das suas infraestruturas e de serviços urbanos, como o caso dos serviços públicos de saneamento básico, que englobam o abastecimento de água potável, a coleta e tratamento de esgoto sanitário, a estrutura para 
a drenagem urbana e o sistema de gestão e manejo dos resíduos sólidos.

Assim, no século XXI no mundo em geral e, particularmente, nas cidades Moçambicanas, a produção dos resíduos sólidos tem aumentado gradualmente de ano para ano, fenômeno que tem sido provocado pelos seguintes fatores: crescimento populacional, consumo excessivo, produtos susceptíveis de produzir resíduos, liberalização do mercado etc. Neste contexto, a implementação da Educação Ambiental no âmbito de desenvolvimento da gestão dos resíduos sólidos é extremamente relevante à medida que possibilita a obtenção de conhecimento formal e informal e sensibilização da comunidade local sobre a consciência adequada que possibilita inverter a degradação ambiental em todos os níveis bióticos e abióticos.

Neste pressuposto, essa situação não foge da realidade vivenciada na região em estudo, pois uns dos grandes problemas atuais que enfrentam a sociedade em geral, nos centros urbanos, particularmente na cidade de Chókwè, relacionam-se com enorme quantidade de resíduos sólidos acumulados a céu aberto em qualquer espaço. Estes, não constitui apenas um problema da ordem estética da cidade, mas também, representam uma série de ameaça à saúde pública por agentes patogênicos, danos indiretos à saúde devido a poluição do ar e das águas subterrâneas, bem como a diminuição de espaço disponível para o lazer público.

Dada esta constatação e descrita nos parágrafos acima, surgem-nos o seguinte problema de investigação: Qual o nível de conhecimento e a prática educativa que pode ajudar no âmbito escolar para a mitigação e a gestão seletiva dos resíduos sólidos? Nesta situação, tendo em conta o problema de investigação levantado o nosso objeto de estudo é a Educação Ambiental no âmbito de desenvolvimento da gestão de resíduos sólidos e análise dos impactos desses resíduos no contexto escolar.

Assim, o interesse em desenvolver esta pesquisa surgiu com objetivo de analisar a contribuição da Educação Ambiental no âmbito de desenvolvimento da gestão de resíduos sólidos de tal forma que os aprendizes possam assumirem atitudes positivas e comportamentos aceitáveis no processo da coleta seletiva do lixo, identificando qual o nível de compreensão em relação ao meio ambiente em seu dia-a-dia.

É neste contexto, que no posicionamento do Logarezzi (2004), defende que:

Para a conscientização da problemática ambiental que se vive em maior parte das regiões urbanas, é indispensável o desenvolvimento de uma Educação Ambiental universalmente que envolva a educação formal e não-formal. A primeira designa às atividades de uma educação participativa realizada no âmbito escolar que pressupõe a formação dos envolvidos. A segunda 
abrange governantes, catadores e cidadãos e prioriza cursos de capacitação e atividades educativas.

Nesta perspectiva, a Educação Ambiental no âmbito de desenvolvimento da gestão dos resíduos sólidos deve constituir o único instrumento que possa participar ativamente para a solução de vários problemas que a população local enfrenta no seu dia-a-dia, proporcionando conhecimento que possibilita a mudança de mentalidade, levando novas visões de observar o mundo planetário, sugerindo boas maneiras de convivências com a natureza, desfazendo as falhas cometidas no passado e identificando problemas socioambientais oriundos de uso inadequado dos resíduos sólidos.

É a partir deste contributo que Zuben (1998), afirma que:

O projeto de coleta seletiva dos resíduos sólidos nas escolas, é de extrema relevância na medida em que possibilita incentivar os aprendizes de diversas culturas étnicas a efetuarem a seleção do lixo, levando esse hábito para suas casas. O mesmo autor, acrescenta que no processo de tratamento de lixo, é necessário que todos os envolvidos tenham perícias adequadas nas atividades de reciclagem dos resíduos sólidos.

Assim, a Educação Ambiental no âmbito de desenvolvimento da gestão dos resíduos sólidos constitui uma componente indispensável para a mudança de atitude das pessoas e deve ser praticada em todos os níveis de escolaridades desde o ensino primário, secundário, técnico profissional etc., proporcionando debates constantes, a inserção das questões da gestão dos resíduos sólidos, as vezes postos de lado, e que são de maior influência para preservação e conservação da biodiversidade no qual estamos inseridos, bem como a responsabilidade onde cada indivíduo e coletividade se torna responsável apenas por suas ações, desfazendo-se suas práticas nocivas sobre o meio ambiente e, consequentemente, consumindo menos e reutilizando embalagens descartáveis, para que possamos servir como exemplos observáveis para muitas instituições educativas.

Neste pressuposto, a gestão dos resíduos sólidos é uma atividade complexa que fundamentalmente dependem de todos os envolvidos na ação, tanto o setor familiar, empresas privadas, setor pedagógico, as autoridades municipais, ONG (Organização Não Governamental), bem como da aplicação seletiva das técnicas adequadas para a coleção, transferência, reciclagem e a disposição final dos resíduos, buscando conceitos, práticas e técnicas, que podem proporcionar o bem-estar da população em geral, melhoria de qualidade da saúde dos munícipes e boas maneiras de convívio equilibrado entre o ser humano e o meio ambiente. 
É nesta perspectiva, que o Carvalho (2004-2005), defende que:

O educador deve estabelecer uma prática social "ultrapassando a fronteira de conversão pessoal e reconversão profissional". O educador ambiental, deve ser um sujeito, o qual pode ser entendido como o conjunto das formas tradicionais (tabus, contos, práticas mágico-religiosas, provérbios etc), que serve de modelo para a identificação social, individual e coletivo dos valores ecologicamente equilibrado, possibilitando a construção da identidade do educador ambiental, repensando em suas atitudes e agindo de maneira correta aos princípios ecológicos na busca de mecanismos apropriados, visando intervir nos problemas e conflitos socioculturais e socioambientais.

E o contributo acima, é também sustentado por Santos (2010), quando ele afirma que:

É extremamente relevante a Educação Ambiental no âmbito de desenvolvimento dos resíduos sólidos, seja trabalhada dentro e fora da escola, elaborando e inserindo projeto que envolvam aprendizes como agente ativo do processo na identificação e mitigação dos impactos negativos que contribuem o surgimento e a acumulação dos resíduos sólidos nas regiões urbanas.

É neste âmbito, que o Cempre (2006), declara que:

Os resíduos sólidos, deve ser difundida tendo como foco os três princípios fundamentais: reduzir, reutilizar, reciclar, desenvolvendo práticas que articulem a Educação Ambiental no âmbito de desenvolvimento de gestão de resíduos sólidos e o meio ambiente, aumentando, responsabilidade e consciência na gestão dos resíduos sólidos

Neste pressuposto, assumimos perante a pesquisa que o presente estudo visa analisar a contribuição da Educação Ambiental no âmbito de desenvolvimento dos resíduos sólidos, de tal maneira que o aprendiz adquira a consciência ativa que possibilita a atuação ecológica sustentada de gestão seletiva dos resíduos sólidos, construindo conhecimento que incorpora boas maneiras de convivências com a natureza, mitigando valores e hábitos irresponsáveis ou insustentáveis sobre o desenvolvimento do meio ambiente.

Assim, a Educação Ambiental no âmbito de desenvolvimento de gestão dos resíduos sólidos deve promover uma ação conjunta que parta do que é do seu domínio social, étnico, económico, para uma política justa à dimensão real 
da situação local, visando impulsionar as transformações de valores, por meio da elaboração de propostas pedagógicas, promovendo o desenvolvimento de capacidade de avaliação e participação dos aprendizes na resolução dos problemas ambientais, particularmente sobre o lixo, seu destino final e possíveis formas de reaproveitamento, colocando em primeiro lugar a mudança de atitudes, práticas socioculturais de vários atores e usuários. Pois, sem essa mudança não será possível falarmos da gestão dos resíduos sólidos na região em estudo.

Acreditamos que a partir desse estudo, existirá vários itinerários credíveis a serem seguidos pelos muitos pesquisadores na construção de um conhecimento individual e coletivo que possibilita alcançar uma gestão adequada dos resíduos sólidos, onde cada parte envolvida tenha maior responsabilidade na identificação dos infratores que levam a degradação do meio ambiente de difícil recuperação.

\section{Educação Ambiental no âmbito de desenvolvimento da gestão dos resíduos sólidos}

Falar dos resíduos sólidos em Moçambique, é o sinônimo de repensar a problemática da degradação ambiental, pois em Moçambique todos os municípios destinam seus resíduos sólidos à disposição a céu aberto, nas chamadas lixeiras ou lixão. Nenhum município do país resolveu efetivamente a gestão dos resíduos sólidos urbanos, pois o modelo tradicional de gestão apresenta uma série de problema, sem trazer soluções satisfatórias à comunidade urbana.

Essa situação não foge da realidade da área de estudo, pois uns dos problemas que assola a cidade de Chókwè, é sem dúvida a deficiência de gestão dos resíduos sólidos urbanos, apesar da gestão dos resíduos sólidos ser da responsabilidade do Conselho Municipal a sua gestão ainda é inadequada desde o condicionamento, recolha, transporte até a disposição final. Essa problemática da gestão dos resíduos, verifica-se principalmente pela inexistência de responsabilidade, conscientização e sensibilização por parte da população local.

Assim, com o aumento dos problemas ambientais que sobressai dia após dia na superfície planetária, a partir do século XVIII devido ao aumento populacional aliado aos avanços tecnológicos, possibilitando transformações na natureza verificada atualmente devido a ação do homem, viu-se a necessidade de mudança de hábito quanto à utilização do meio ambiente pela comunidade em geral. Portanto, houve a necessidade de incorporação de novas maneiras de convivências com a natureza, contribuindo para o surgimento da Educação Ambiental como parte integrante indispensável na mudança comportamental do homem em relação a sua atuação ao meio ambiente. 
É neste âmbito, que as discussões realizadas na Conferência RIO/92, decidiram que:

Em 1972, os problemas ambientais fossem colocados na mesa na Conferência das Nações Unidas de Meio Ambiente Humano, realizada em Estocolmo. Nessa Conferência, foram discutidos problemas do aumento de poluição gerado pelo crescimento populacional, industrial, originando as primeiras políticas de gerenciamento ambiental e também o estabelecimento do Programa Internacional de Educação Ambiental. Partindo dai, este programa internacional foi consolidado em 1975 na Conferência de Belgrado (BRASIL, 2001).

Aliando-se, também da proposta do Relatório da Fundação Alemã de População Mundial (2014), vem completar o pensamento das discussões realizadas na Conferência RIO/92 (Brasil, 2001), quando esclarece que:

A população teve um aumento de 80 milhões de pessoas do ano 2013 para 2014, possuindo no mundo atualmente 7,2 bilhões de pessoas. Todos estes fatores interferem significativamente na saúde do planeta e se intensifica quando ocorre a má gestão dos resíduos sólidos provocando inúmeras doenças, problemas sanitários relacionados à poluição do ar, o assoreamento dos rios e contaminação da água, entre outros.

Por sua vez, Bidinoto (2009), defende que este problema torna mais agravante se considerarmos "o tempo da decomposição de alguns materiais que variam dependendo do tipo de resíduo como o caso: de Plástico, 450 anos; vidro, 5.000 anos; alumínio, 100 anos etc.". Portanto, não se esqueça de que tudo o que deitamos fora foi feito a partir de um dos recursos naturais da terra planeta, exemplo: O plástico a partir do óleo, o vidro a partir de areia, o papel a partir das árvores, latas a partir do metal etc.

Neste pressuposto, chama atenção aos usuários que a reciclagem, constitui uma das melhores alternativas para minimizar o problema dos resíduos sólidos em qualquer parte do mundo, principalmente nos países em via de desenvolvimento. Todavia, é necessário que cada pessoa ou coletividade esteja preparado psicologicamente para este desafio, tendo em conta que o lixo é fonte de riqueza e que para ser reciclado precisa ser separado de diversas maneiras: separar o lixo orgânico do inorgânico.

É diante disso que Philippi (1999), define que os resíduos sólidos, trata-se de uma "mistura de minerais ou resto destes, oriundos dos diversos tipos de atividades praticadas pelo homem que são descartados pelo fato de não possuírem utilidades necessárias à sociedade". 
Dias (2002) vem completar à ideia Philippi (1999), definindo os resíduos sólidos como:

Materiais rejeitados nas atividades domésticas, comerciais e de serviços que englobam materiais com diversas caraterísticas desde os resíduos inertes (entulhos provenientes de obras e demolições), orgânicos provenientes de consumismo de alimentos, embalagens de livros, plásticos, metal, papel/papelão e até recursos perigosos como embalagens de tintas e óleos, bem como aqueles com caraterísticas de resíduos de serviços de saúde.

É neste contributo que o Furreiela (2002), defende que:

Uma melhor gestão dos resíduos sólidos, seria necessário que os governos locais, nacionais, regionais e internacionais estejam bem informados sobre a degradação do meio ambiente, possibilitando a capacitação da sociedade em geral na prática de tratamento de resíduos sólidos que incluem: redução e reutilização, reciclagem, compostagem, incineração etc., de forma que tenham conhecimentos sobre a relevância da gestão do meio ambiente na perspectiva da busca de alternativas viáveis que possibilitem a melhorar a qualidade de vida da população e a diminuição de impactos do uso inadequado do meio ambiente, facilitando a gestão dos resíduos sólidos.

É aqui onde a Educação Ambiental no âmbito de desenvolvimento da gestão dos resíduos sólidos, apresenta o seu contributo demonstrando o seu papel nos aspectos teóricos e práticos, proporcionando novas maneiras de convivências com a natureza, possibilitando os aprendizes construírem um conhecimento que permita compreender os conteúdos da gestão dos resíduos sólidos a partir da pesquisa e ações coletivas, promovendo atitudes positivas, assegurando que este meio ambiente, seja utilizado pelas gerações vindouras.

Assim, a Educação Ambiental no âmbito de desenvolvimento da gestão dos resíduos sólidos deve constituir a condição fundamental para sensibilizar as pessoas do mundo em geral sobre a sua maneira de pensar e utilizar o meio ambiente, participando como mediador, onde o professor desempenha a sua tarefa de facilitador desse processo e os currículos escolares devem ser elaborados de tal forma que haja a interdisciplinaridade colocado o aprendiz como agente ativo do processo, visando alcançar a gestão dos resíduos sólidos onde todos munícipes sintam-se a responsabilidade de preservação do meio ambiente. 
É neste pressuposto que aparece Agenda 21, propondo vários programas que possibilitam o gerenciamento efetivo dos resíduos sólidos:

Minimização da geração de resíduos, maximização de práticas de reutilização e reciclagem, implementação de sistemas de tratamento e disposição de resíduos, compatíveis com a preservação ambiental, extensão da cobertura dos serviços de coleta e destino final dos resíduos, possibilitando alcançar um nível de consciência ambiental que propõe soluções comprometidas com 0 desenvolvimento sustentável sem a destruição total dos recursos naturais dos ecossistemas dos quais depende a vida (SISINNO; OLIVEIRA, 2000).

Nesta óptica, as campanhas educativas constituem uma componente relevante para mobilizar a comunidade em geral sobre a sua participação em massa e ativa na coleta seletiva dos resíduos sólidos, separando os materiais recicláveis e reutilizáveis diretamente na fonte de geração, despertando a responsabilidade da sociedade para ações básicas de proteção ao meio ambiente e a geração de trabalho, pois atualmente os resíduos sólidos, passaram a ter influência no âmbito social e econômico estando relacionado com a coleta, venda dos reciclados e renda para a população desfavorecida.

Nesta perspectiva, a gestão dos resíduos sólidos na cidade de Chókwè, deve englobar etapas que buscam argumentos para evidenciar que a Educação Ambiental, especialmente a desenvolvida no âmbito da gestão de resíduos sólidos dentro da sala de aula, constitui componente importante na formação de novos valores e atitudes frente à problemática ambiental. Portanto, a Educação Ambiental na escola, deve refletir as suas atividades pedagógicas e interdisciplinares, desempenhando as suas funções em formação de indivíduos conscientes e aptos a exercerem os seus planos à médio e longo prazo que incluem a participação dos aprendizes, serviços de limpeza, transporte, recursos humanos qualificados capazes de direcionarem a coleta, seleção, tratamento e destino final dos resíduos que reduzam os impactos nefastos ao meio ambiente

\section{Gestão dos resíduos sólidos na escola}

A acumulação de resíduos sólidos a céu aberto, feita de forma inadequada nas cidades moçambicanas, pode provocar vários problemas de saúde dos munícipes, devido às contaminações de recursos hídricos, proliferação de vetores transmissores de doenças, contaminação de alimentos, entre outros problemas como contaminação do solo, assoreamento do Rio Limpopo que o circunda o local em estudo. 
Essa situação não foge da realidade vivenciada no Instituto Agrário de Chókwè, pois como sendo uma instituição de ensino, produz diferentes tipos de resíduos sólidos oriundos de várias atividades tais como: limpeza, produção de alimentos, atividades administrativas, salas de aulas, entre outros resíduos. Para evitar esse mal, é necessário adequar as políticas públicas, e fornecer alternativas viáveis de tratamento eficiente dos resíduos sólidos.

É neste posicionamento que Freire (1999), defende que "a escola como sendo local de convivência social possibilita os professores, aprendizes de diversas etnias sociais, religiosas enfrentar o desafio na busca de uma prática transformadora na qual homens e mulheres se tornam sujeito de sua própria educação".

Soares, Salgueiro e Gazineu (2007) declaram que:

A Educação Ambiental, deve constituir um instrumento fundamental individual ou coletivo, visando desenvolver uma consciência crítica em relação ao meio ambiente, gerando comportamento e responsabilidade na resolução dos problemas associados aos resíduos sólidos, desde a geração, coleta, transporte até a disposição no destino final.

Assim, tomando em consideração que o Instituto Agrário de Chókwè, recebe aprendizes de diversas culturas, hábitos e costumes, etnias e de baixa renda econômica familiar, muitas vezes vindo do interior sem conhecimento da consciência sobre a gestão dos resíduos sólidos, sugere-se que pais e encarregados de educação, professores e, sobretudo, o Ministério de Ciência e Tecnologia, ensino Superior e Técnico Médio Profissional, busque métodos adequados que possibilitam à incorporação nos programas escolares conteúdos ecológicos que abordam questões de preservação, incentivo, a conscientização, e renovam/desenvolvam recursos tecnológicos em sala de aula de forma a não poluir o meio ambiente segundo os termos do artigo 9o da Lei do Ambiente, que advoga o seguinte:

Não é permitida, no território nacional, a produção, o depósito no solo e no subsolo, o lançamento para a água ou para a atmosfera, de quaisquer substâncias tóxicas e poluidoras, assim como a prática de atividades que acelerem a erosão, a desertificação, o desflorestamento, ou qualquer outra forma de degradação do ambiente, fora dos limites legalmente estabelecidos. 
conteúdos básicos do tratamento de qualquer tipo de resíduos, permitindo descobrir o que é positivo ou negativo, aos poucos mudar a sua mentalidade que possibilita obter à autoconfiança de aprender a viver no ambiente limpo e sustentável.

\section{Metodologia}

Muitas instituições que lidam com os resíduos sólidos urbanos em Moçambique, desde o nível central até na base tem apresentando várias limitações/dificuldades orçamentais consequentemente não tem cumprido as suas atividades planificadas, bem como observa-se a fraca Educação Ambiental e participação dos setores privados, públicos e sociedade civil na gestão dos resíduos sólidos.

Assim, para resolver os problemas da gestão dos resíduos na cidade de Chókwè particularmente no Instituto Agrário de Chókwè, é necessário almejar os conhecimentos formais e informais, divulgando a metodologia adequada que possibilita perceber os graves problemas ambientais e de saúde oriundos da gestão inadequada dos resíduos sólidos.

Portanto, a pesquisa em causa é "qualitativa, com abordagem descritiva, exploratória, empírica. Pois, com base desta pesquisa permitiu fazer a observação, seleção, consolidação, análise documental, interpretação de entidades que por sua vez, interpretam o mundo que as rodeiam" (MOREIRA, 2002, p. 50-1). Para o efeito, foi realizado a entrevista semiestruturada através de contato direto com os vendedores fixos ou ambulantes, os formandos, agentes públicos, professores e a comunidade em geral, visando identificar a quantidade e tipo de resíduo gerado pelos munícipes e pela escola.

Participaram na entrevista aprendizes do curso de Agropecuária, com uma amostra de 27 formandos subdividas entre homens e mulheres.

\section{Resultados}

Participaram na entrevista 90 aprendizes do primeiro, segundo e terceiro ano do curso de Agropecuária, com uma amostra de 27 formandos subdividas em dois grupos: $1^{\circ}$ ) $55.6 \%$ dos homens questionados sobre os métodos de tratamento dos resíduos sólidos, declararam não separar ou reaproveitar os resíduos gerados em sua casa e na escola; Produzir em maior quantidade os resíduos do tipo Papel/Papelão. Pois, o papel é visto como principal resíduo gerado no Instituto Agrário, pelo facto dos discentes escreverem rascunhos para o estudo dos instrumentos de avaliação, fotocópias de apontamentos.

$2^{\circ}$ ) $44.4 \%$ das mulheres indagadas sobre o destino final dos resíduos sólidos, responderam que o lixo é queimado e enterrado e para a mitigação da sua proliferação, preferem que seja por meio de palestras, por meio de trabalhos educacionais, por vídeos que ilustram a degradação do meio ambiente, bem 
como o uso de livro contendo conteúdos que versam a Educação Ambiental no âmbito de desenvolvimento de gestão dos resíduos sólidos, possibilitando o domínio de conhecimento do manejo dos resíduos sólidos e a reflexão da problemática ambiental de "deita fora", prejudicando a saúde pública dos munícipes da cidade de Chókwè.

Neste pressuposto, percebe-se que os formandos desconhecem a relevância da gestão dos resíduos sólidos, apresentam hábitos que devem ser melhorados para evitar maior degradação ao meio ambiente e precisam uma Educação Ambiental no âmbito de desenvolvimento de gestão dos resíduos sólidos, o que possibilitará os aprendizes compreenderem a componente fundamental da conscientização do meio ambiente que decorre por meio da inserção de políticas ambientais na comunidade escolar.

Assim, a partir de nosso contato pessoal e experiência vivida enquanto oficial da contra inteligência, justiça e disciplina militar com patente de capitão das Forças Armadas de Defesa de Moçambique em contato com o campo da pesquisa, junto os vendedores do mercado local, ambulantes, aprendizes, a comunidade em geral, sobretudo professores, com ajuda da entrevista semiestruturada através da pesquisa descritiva, empírica, exploratória de natureza qualitativa afirmam que é comum encontrar situações alarmante pelo grau de magnitude de visualização de resíduos espalhados na cidade de Chókwè em determinado período do dia ou da semana.

Na região em estudo (Instituto Agrário de Chókwè), é notório verificar cadeiras quebradas, jogadas no quintal da escola, papel, latas, copos plásticos, resto de comida, enfim um conjunto de resíduos sólidos despejados no meio ambiente (Figura 1), sem a menor preocupação de promover uma consciência e cultura ambiental, bem como as consequências que estes resíduos acumulados sem nenhum tratamento venha trazer para os aprendizes e para a comunidade em geral circunvizinha.

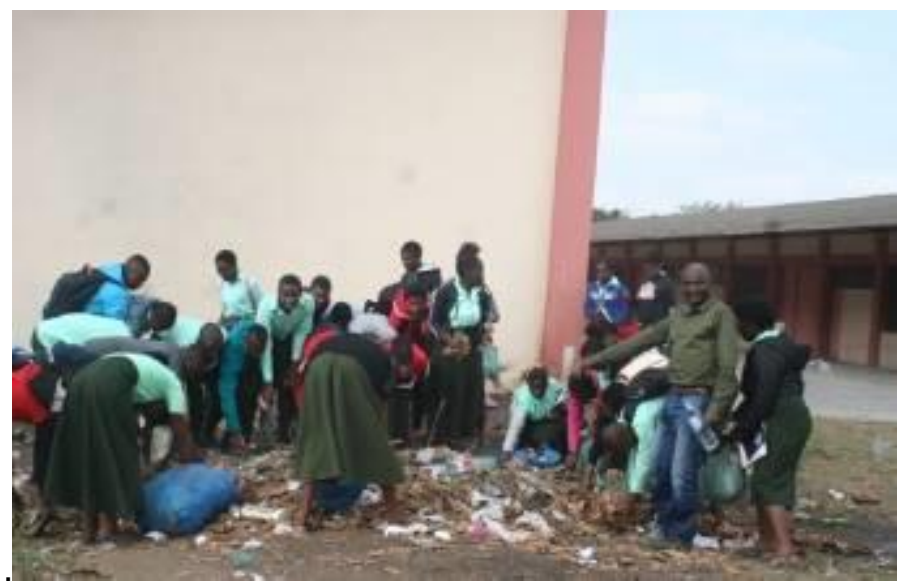

Figura 1: ilustra o lixo a céu aberto acumulado no local inapropriado². Fonte: Acervo próprio, 2018.

2 A Figura 1, auxiliou para que compreendêssemos claramente que com o ensino-aprendizagem de Educação Ambiental no âmbito de desenvolvimento da gestão dos resíduos sólido, é possível conscientizar 
É nesta ilustração acima, que aparece o contributo do Loureiro (2009), afirmando que:

A Educação Ambiental no âmbito de desenvolvimento de gestão dos resíduos sólidos, constitui uma prática que dialoga com as questões ambientais. Essa educação, visa a mudança de valores, atitudes, e comportamento para estabelecimento de uma consciência que possibilita conscientizar os aprendizes de forma que não joguem no quintal da escola todo tipo de resíduo sólido, sentindo responsabilidade pelo uso adequado dos resíduos, tornando harmonioso aos limites ecológicos [...].

Para a resolução desta situação vivenciada na cidade de Chókwè particularmente na região em estudo, é necessário o envolvimento da escola, pais e encarregados de educação, governo local, maior coordenação intermunicipal na gestão dos resíduos sólidos, capacitação dos recursos humanos em todos os níveis, melhoramento de equipamento e transporte, melhorar as infraestruturas de disposição final, incentivar o setor privado, público e a sociedade civil sobre a gestão dos resíduos sólidos. Para isso, o País precisa de uma política que contemple seleção, reciclagem, reutilização e o gerenciamento dos resíduos. Apesar do Ministério da Terra, Ambiente e Desenvolvimento Rural, desenvolver várias atividades como órgão consultivo e deliberativo responsável por assessorar e propor ao Conselho de Governo, diretrizes de políticas governamentais para o meio ambiente e para os recursos naturais.

Nesta perspectiva, a Educação Ambiental no âmbito de desenvolvimento de gestão dos resíduos sólidos deve ser trabalhada tanto na educação formal e informal de tal forma que possa responder a demanda da sensibilização à comunidade em geral, com relação aos resíduos sólidos. A escola, deve constituir um "lugar apropriado para a abordagem de temas relacionados à ecologia, saúde, higiene, preservação do meio ambiente e cidadania" (BRITTO, 2000).

Nesse sentido, nossa preocupação fundamental recai sobre os resíduos sólidos, para a implementação da gestão integrada que possibilita o envolvimento de todos na busca de uma Educação Ambiental saudável, onde cada indivíduo ou coletividade sinta-se responsável em fazer algo para conter o avanço do processo "deita fora" os resíduos sólidos, colocando o aprendiz como

os aprendizes sobre a coleta do lixo a céu aberto, prejudicando a saúde pública da comunidade escolar, Para o destino final apropriado distante do recinto escolar. 
agente ativo no processo da apresentação das opiniões e alternativas para implementação do programa adequado da gestão dos resíduos sólidos.

É neste sentido, que torna necessário o uso do Decreto n. 0 13/2006, de 15 de junho de 2006, "Regulamento sobre Gestão de Resíduos Sólidos", pelo fato de ser uma diretiva que procura abordar e esclarecer efetivamente as questões dos resíduos sólidos.

\section{Considerações finais}

No início do século passado, o crescimento da atividade cotidiana, acompanhada pela inexistência de uma norma orientada à proteção do meio ambiente, propiciou maior produção de resíduos sólidos na terra planeta, contribuindo a contaminação do meio ambiente de difícil recuperação na atualidade.

Assim, a partir de análise de conteúdo, segundo Bardin (1977, p. 42), permitiu obter registros orais e escritos, a escolha dos softwares utilizados, os participantes, visando realizar a pesquisa qualitativa com abordagem exploratória, empírica, descritiva através da entrevista semiestruturada junto as comunidades locais com a finalidade de analisar a contribuição da Educação Ambiental no contexto de desenvolvimento da gestão da coleta seletiva do lixo, identificar a quantidade e tipo de resíduo gerado pela escola e pelos munícipes, bem como fundamentar que foi possível trazer algumas contribuições teóricopráticas ao grupo-alvo, para o futuro ambiental local: Falta de sensibilização/consciência ambiental por parte da comunidade local sobre o desenvolvimento sustentável da gestão dos resíduos sólidos e com as normas existentes, como base de política ambiental; Existência de carência de serviços de limpeza pública oferecidos pelo município, o que normalmente desestimula os aprendizes a separação dos resíduos, já que não há coleta seletiva; A ausência de ações e a negligência por parte dos governos locais também contribuem consideravelmente para o agravamento da situação dos resíduos sólidos urbanos.

Desta forma, a responsabilidade da gestão dos resíduos sólidos é de todos munícipes, pois não basta o Conselho Municipal de Chókwè ter uma estrutura orgânica completa e pronta para responder todas demandas, é necessário que a comunidade em geral participe efetivamente na busca das soluções e tomadas das decisões frente às problemáticas ambientais, de tal forma que cada munícipe sinta maior responsabilidade individual e coletivo na gestão e mudança de hábitos e costumes em relação ao problema de acumulação de lixo a céu aberto sem nenhum tratamento, proliferando diversas doenças à população local.

Neste sentido, a escola torna-se um lugar ideal para a construção de conhecimento formal e informal que possibilita a formação de indivíduo capaz de analisar fatos e situações de todos os tipos de resíduos do ponto de vista 
ambiental, obrigando o aprendiz a encontrar as estratégias adequadas que possibilitam a coleta, seleção, reciclagem, reutilização e a disposição do destino final.

Assim, Pais e encarregados de educação, comunidade em geral, sobretudo professores, cabe ensinar e conscientizar os aprendizes sobre os aspectos positivos e negativos de preservação do meio ambiente, trabalhando temas de gestão dos resíduos sólidos em todas as disciplinas como algo novo, facilitando os aprendizes examinar as principais questões de gestão dos resíduos sólidos no ponto de vista local (Figura 2).

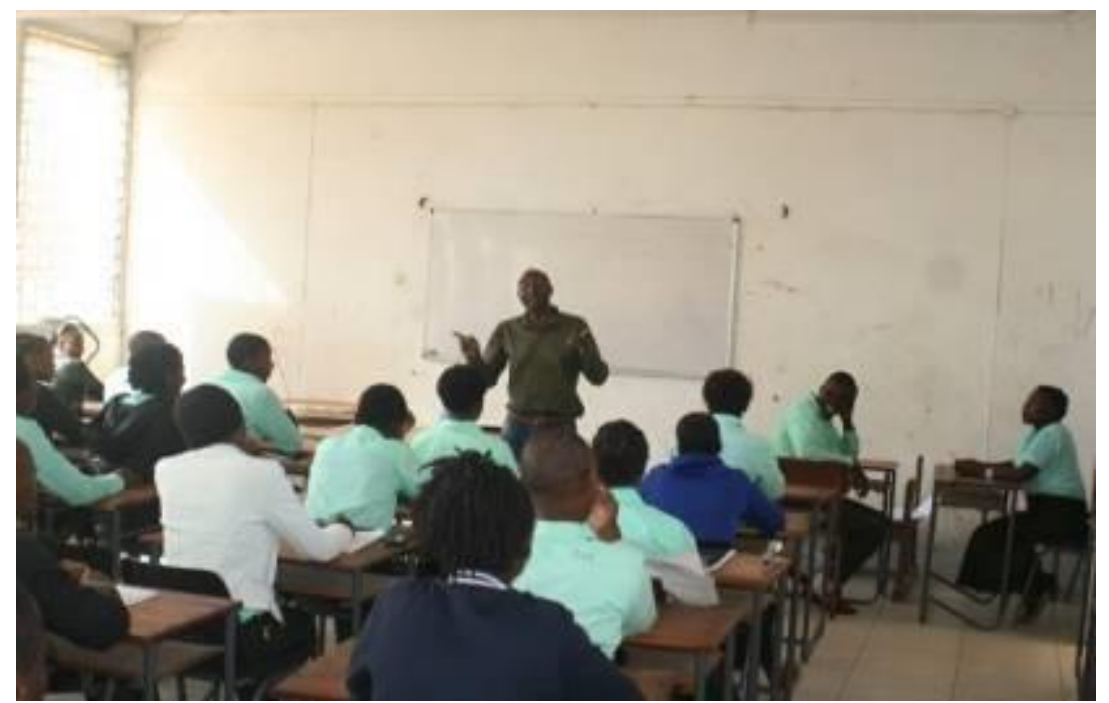

Figura 2: Ilustra o autor a dar palestra de Educação Ambiental aos aprendizes do primeiro ano do curso de Agropecuária do Instituto Agrário de Chókwé3. Fonte: Acervo próprio, 2018

Nesta perspectiva, torna importante o uso da lei das Autarquias locais, Lei n. $-2 / 97$, de 18 de Fevereiro que atribui aos munícipes competência que possibilita a busca do desenvolvimento local com qualidade ambiental, conferida da seguinte forma:

- Promoção da Educação Ambiental no contexto de desenvolvimento de gestão dos resíduos sólidos, valorizando a preservação, prevenção, reciclagem, reutilização e planejamento ambiental, através de taxas de licenciamento e multas;

- Autonomia quanto ao licenciamento ambiental e controle dos impactos ambientais locais.

3 A Figura 2, ajudou explicar in loco ou presencialmente aos aprendizes a relevância da Educação Ambiental na gestão dos resíduos sólidos, possibilitando aos aprendizes construir a consciência individual ou coletivamente de viver no ambiente limpo sem perturbação dos resíduos sólidos que futuramente poderá prejudicar a saúde pública. 
Portanto, a Educação Ambiental no contexto de desenvolvimento da gestão de resíduos sólidos deve ser vista como um processo de constante aprendizagem que valoriza as diversas formas de conhecimentos, habilidades e competências, visando formar cidadão comprometida com a redução de maior quantidade de resíduos sólidos que deveriam ser jogados na superfície terrestre e marítimo sem tratamento adequado, perigando a vida humana, bem como todos os seres vivos cuja a sua sobrevivência dependem fundamentalmente do meio ambiente.

Assim, o educador deve estar preparado psicologicamente para lidar com novas metodologias, visando promover na comunidade escolar o interesse dos aprendizes para uma gestão qualificada dos resíduos sólidos que tanto vem prejudicando o nosso dia a dia, trabalhando de forma interdisciplinar, promovendo a sensibilização, incentivo e participação de todos na busca de um ambiente conservado, limpo e sustentável que possibilita uma convivência harmoniosa com a natureza.

Cabe salientar que o Conselho Municipal do Distrito de Chókwè, junto com seus munícipes, tem criando esforço bastante positivos na busca das alternativas viáveis de gestão dos resíduos sólidos, apesar das insuficiências dos recursos materiais, técnicos, humanos e financeiros, que possam assegurar uma boa sustentabilidade do meio ambiente onde estão inseridos todos os munícipes.

Para finalizar, pensamos que com a campanha educativa, divulgação das normas que orientam a gestão dos resíduos, respeito às contribuições das comunidades locais, aprendizes, sobretudo professores e de todos os envolvidos, é possível realizar a coleta seletiva e a reciclagem de resíduos, sendo uma solução indispensável, pelo facto de permitir a redução do volume de lixo para disposição final em aterros e incineradores.

\section{Referências}

BRITTO, C. Educação e Gestão Ambiental. Salvador: Ministério do Meio Ambiente, 2000.

BIDINOTO, V.M. A Importância da Reciclagem. Você contribui com o meio ambiente e com a sua própria vida? 2009.

BARDIN, L. Análise de conteúdo. Lisboa: Edições 70. 1977

BRASIL. Parâmetros Curriculares Nacionais: meio ambiente: saúde. 3. ed Brasília-DF: Ministério da Educação. Secretaria da Educação Fundamental, 2001.

CARVALHO, I.C.M. Educação Ambiental: a formação do sujeito ecológico. São Paulo: Cortez, 2004. 
CARVALHO, I.C.M. A invenção do sujeito ecológico: identidades e subjetividade na formação dos educadores ambientais. In: SATO, M.; CARVALHO, I.C.M. (orgs). Educação Ambiental: pesquisa e desafios. Porto Alegre, Artmed, 2005.

CEMPRE - Compromisso Empresarial para a Reciclagem. Programa Bio Consciência. Lixo municipal - Manual de Gerenciamento Integrado. Brasília: CEMPRE, 2006.

DIAS, M. F. S. caracterização física dos resíduos sólidos urbanos: uma etapa preliminar no gerenciamento do lixo. Anais do XVIII Congresso Internacional de Inginiéria Sanitaria y Ambiental. Cancún, México, 2002.

FREIRE, P.; ,NOGUEIRA, A.. Teoria e Prática em Educação Popular. Petrópolis: Vozes, 1999.

FURRIELA, R.B. Democracia, Cidadania e Proteção do Meio Ambiente, 2002.

LOUREIRO, C.F.; LAYRARGUES, P.P.; CASTRO, R.S. (orgs.). Repensar a Educação Ambiental: um olhar crítico. São Paulo: Cortez, 2009.

LOGAREZZI, A.J.M. Contribuições conceituais para o gerenciamento de resíduos sólidos e ações de Educação Ambiental. In: LEAL, A.C. et al. (Org.) Resíduos sólidos no Pontal do Paranapanema. Presidente Prudente: Antônio Thomaz Júnior, 2004.

MAPUTO. (Município). Decreto n.o 13/2006, de 15 de junho de 2006. [Maputo], que aprova o Regulamento sobre Gestão de Resíduos Sólidos.

MAPUTO (Município). Plano Director da Gestão de Resíduos Sólidos Urbanos da Cidade de Maputo. Maputo, 2008.

MOÇAMBIQUE. Assembleia da República. Lei 2/97, de 18 de Fevereiro. Aprova a lei das autarquias locais. Boletim da República, Maputo, I série n. 7, 18 fev. 1997.

MOREIRA, D.A. O método fenomenológico na pesquisa. São Paulo: Pioneira Thomson, 2002.

PHILIPPI. JR., A. A. Agenda 21 e Resíduos Sólidos. In: Seminário sobre Resíduos Sólidos, 1. São Paulo: Páginas e Letras Editora e Gráfica Ltda, 1999.

RELATÓRIO DA FUNDAÇÃO ALEMÃ DE POPULAÇÃO MUNDIAL, 2014

SANTOS, H.M.N. BORGES, A.A.S; CÂNDIDA, A.C.; FEHR, M. Educação Ambiental e resíduos sólidos em Araguari/MG - Brasil. Revista da Católica, Uberlândia, v. 2, n. 3, 2010.

SISSINO, C.L.S.; OLIVEIRA, R.M. (Orgs.) Resíduos Sólidos, Ambiente e Saúde: uma visão multidisciplinar. Rio de Janeiro: Editora FIOCRUZ, 2000. 
SOARES, L.G.C.; SALGUEIRO, A.A.; GAZINEU, M.H.P. Educação Ambiental aplicada aos resíduos sólidos na cidade de Olinda, Pernambuco: um estudo de caso. Centro de Ciências e Tecnologia, Universidade Católica de Pernambuco. Recife, 2007.

SILVEIRA, P.C. Algumas considerações sobre a Lei do Ambiente em Moçambique. Beira. 2010. GEOUSP, 2010

SENE, E. MOREIRA, J.C. Trilhas da Geografia: a Geografia no dia-a-dia. 5a Série. São; Paulo: Scipione, 1998.

ZUBEN, F.V. Meio Ambiente, Cidadania e Educação. Departamento de Multimeios. Unicamp. Tetra Pak Ltda. 1998. 